University of Nebraska - Lincoln

DigitalCommons@University of Nebraska - Lincoln

Congreso internacional sobre iconografía

precolombina, Barcelona 2019. Actas.

$8-21-2020$

De la Atlántida clásica a la Atlántida precolombina: un viaje del

Corto Maltese

Isabel Bargalló Sánchez

Montserrat Bargalló Sánchez

Follow this and additional works at: https://digitalcommons.unl.edu/actas2019

Part of the American Material Culture Commons, Indigenous Studies Commons, Museum Studies Commons, Other History of Art, Architecture, and Archaeology Commons, and the Other Languages, Societies, and Cultures Commons

This Article is brought to you for free and open access by the Zea E-Books at DigitalCommons@University of Nebraska - Lincoln. It has been accepted for inclusion in Congreso internacional sobre iconografía precolombina, Barcelona 2019. Actas. by an authorized administrator of DigitalCommons@University of Nebraska - Lincoln. 


\title{
De la Atlántida clásica a la Atlántida precolombina: un viaje del Corto Maltese
}

\author{
Isabel Bargalló Sánchez y Montserrat Bargalló Sánchez
}

Grup d'Estudis Precolombins. UAB.

isabelbargallosanchez@coac.net; mobasa69@gmail.com

\begin{abstract}
Resumen
Hugo Pratt fue un virtuoso de la plasmación de símbolos e ideas a través de unas viñetas inigualables y de unos guiones insuperables y perfectamente documentados. Su última novela gràfica, Mû, el misterio del continente perdido, es el viaje de Corto Maltese a tierras mesoamericanas, de su encuentro con Mû, con las colonias que quedaron después de su destrucción, con unas referencias al mundo de los antiguos mayas, pero también a otros pueblos de Mesoamérica, muy bien construidas. Con una simbología muy cuidada, eligiendo rigurosamente los referentes, nos acerca a una historia de Mû, de la Atlántida, de las teorías sobre su existencia y desaparición que se entrecruzan con un tratamiento entre irónico i paródico de las obras de William Blake, Donnelly o Churchward.
\end{abstract}

Palabras clave: Iconografía, Mesoamérica, Atlantis, Hugo Pratt, Corto Maltese

\begin{abstract}
Hugo Pratt was a virtuoso of the expression of symbols and ideas through unmatched vignettes and unsurpassed and perfectly documented scripts. His latest "graphic novel", Mû, the mystery of the lost continent, is the journey of Corto Maltese to Mesoamerican lands, of his encounter with Mû, with the colonies that remained after their destruction, with well-constructed references to the world of the ancient Mayans, but also to other peoples of Mesoamerica. With a very careful symbology, choosing rigorously the referents, brings us closer to a story of Mû, of Atlantis, of the theories about its existence and disappearance that intersect with an ironic and parodic treatment of the works of William Blake, Donnelly or Churchward.
\end{abstract}

Keywords: Iconography, Mesoamerica, Atlantis, Hugo Pratt, Corto Maltese

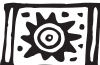

"De la literatura lo que más me llega es la poesía, porque la poesía es sintética y procede por imágenes. Cuando leo, veo imágenes, las percibo a flor de piel. Tras la poesía se esconde una profundidad que puedo sentir inmediatamente y, como en la poesía, el cómic es un mundo de imágenes, se ve uno obligado a combinar dos códigos y, en consecuencia, dos mundos. Un universo inmediato a través de la imagen y un mundo inmediato a través de la palabra." Conversación con Hugo Pratt, diciembre de 1989
\end{abstract}

\section{Introducción}

En agosto de 1988, Hugo Pratt habla con Dominique Petitfaux sobre la nueva aventura de Corto Maltés, MÛ, de la que acaba de publicar la primera parte.

-¿Has vuelto a leer a Churchward para hablar de Mû? "Precisamente he leído varias cosas aprovechando un viaje a la Isla de Pascua. Churchward explica cosas interesantes de forma extravagante, pero no podemos olvidar al guionista William Ritt y al dibujante Clarence Gray, autores del cómic Brick Bradford. Crearon historias formidables que no tuvieron mucho éxito, historias dentro del mismo género literario que Flash Gordon y Buck Rogers, que fueron el punto de partida. En Italia el referente fue Saturno contra la Tierra de Scolari. Precisamente, uno de los primeros cómics que me gustó es Brick Bradford, que narra aventuras ambientadas en la época precolombina." ${ }^{1}$

1. PRATT, HUGO. Corto Maltese: Mû. Norma Editorial, 2008. Este texto pertenece al prólogo, que ha sido extraido del libro All'ombra di Corto. Hugo Pratt -conversazioni con Dominique Petitfaux- Rizoli, Milano Libri 1992.

Publicado en Congreso internacional sobre iconografía precolombina, Barcelona 2019. Actas, Victòria Solanilla Demestre, editora (Lincoln, Nebraska: Zea Books, 2020). https://doi.org/10.32873/unl.dc.zea.1251 
Hugo Pratt creó uno de los personajes más conocidos de la novela gráfica europea o, como él la llamaba, de la literatura dibujada. En efecto, Pratt está considerado uno de los mayores exponentes mundiales de la letteratura disegnata término que él mismo acuñó y seguramente ha sido uno de los autores y dibujantes más prestigiosos del mundo 2 . Su personaje, prototipo del héroe romántico, es el marino Corto Maltese, que en su última aventura se encuentra con el continente perdido. Un continente que, tratándose de Mû, se halla en el Pacífico; pero una de sus colonias más importantes se sitúa geográficamente en las tierras mayas. ¿Por qué, de tantos mitos y lugares perdidos existentes, Pratt elige Mû para la última aventura del Corto? Quizás por lo que él mismo le comenta a Dominique Petitfaux: se siente fascinado por el mundo precolombino. 0 más exactamente, le interesa el modo en que se ha llevado ese mundo al cómic.

Efectivamente, en el primer tercio del siglo XX Ritt y Gray recrean las antiguas civilizaciones americanas en las aventuras de su héroe intergaláctico Brick Bradford ${ }^{3}$. Scolari con Saturno contra la Tierra ${ }^{4}$ vuelve a la antigua América y también es un referente para Pratt.

Sin lugar a dudas, la parte más importante del libro que estamos analizando es el viaje iniciático del protagonista, pero ello no impide que, como nos recuerda Ivan Pintor, las historias del Corto "permitirían reconstruir, como un friso enciclopédico, los caminos de la historia y la geopolítica del siglo XX desde los años treinta a los setenta, los álbumes de Corto Maltés proponen el ejercicio de una fabulación inscrita en la historia con una época en este caso pasada para su autor, las primeras tres décadas de ese siglo XX". ${ }^{5}$
En efecto, en los 15 volúmenes que forman la serie de aventuras de este marino, podemos encontrar al protagonista en Manchuria (en la época de la guerra ruso-japonesa); en Europa durante la Gran Guerra, en la Unión Soviética y en toda América.

En el caso de América, hay pocos autores que hayan abordado nuestro continente desde tantas facetas y tan extensamente: etnografía, historia, arqueología, $[. . .]^{6}$

Además, como ya hemos apuntado anteriormente, en las aventuras del Corto el mundo esotérico y mágico está siempre presente, en una u otra forma, pero es en Mû donde va más allá y nos lleva a una esfera que complica la vida del lector, desorientándolo ${ }^{7}$, tal y como nos indica Sergio Brancato.

Podemos afirmar con Ivan Pintor que:

Corto Maltese "emprende aventuras concebidas como excursiones a un territorio simbólico fraguado a partir de la mecánica del encuentro con personajes históricos, dispuestos a explicarle porque se hallan donde se hallan". ${ }^{8}$

Y esta última aventura,

[...], es un relato que recrea fuentes diversas en torno a la pretendida existencia de un continente desaparecido en los albores del neolítico, desde el mito de la Atlántida hasta las fantasías arqueológicas de escritores, viajeros y ocultistas de finales del siglo XIX y principios del XX como Augustus Le Plongeon y James Churchward. Concebido como un viaje al más allá, Mû confronta a Corto con

2. ROMANO MARTÍN, YOLANDA, 1975-2015 autores y personajes del cómic italiano en España, Transfer XI: 1-2 (mayo 2016), pp. 59-85.

3. Brick Bradford fue una tira diaria aparecida en los Estados Unidos en agosto del año 1933 distribuida por el King Features Syndicate. El protagonista Brick Bradford puede desplazarse por el espacio y el tiempo acompañado de su prometida Béril Salisbury y su amigo Buck O’Brien.

4. Publicada por la editorial Nerbini, Federico Pedrocchi fue el guionista y Giovanni Scolari, el dibujante.

5. PINTOR IRANZO, IVAN, El intervalo alucinatorio en las aventuras de Corto Maltés, de Hugo Pratt: la figuración de la palabra y la discontinuidad visual, H-ermes. Journal of Communication, H-ermes, J. Comm. 6 (2015), 31-58, pp 32.

6. PURINI, SERGIO, L'Amérique plurielle de Hugo Pratt en Hugo Pratt. Lignes d’horizons, Catálogo de la exposición. Musée des Confluences, Lyon 2018, 102-139. pp 103

7. BRANCATO, SERGIO, Il diradarsi e il dissiparsi. Il rapporto di Pratt con il pubblico nella serialità-non seriale di Corto Maltese, $H$ ermes. Journal of Communication, H-ermes, J. Comm. 6 (2015), 9-18, pp. 17

8. PINTOR IRANZO, IVAN, O Somma Luce. Viajes al más allá y encuentros con la Diosa. Una aproximación comparada de la herencia dantesca en los cómics de Pratt, Fellini y Manara y Makyo, Dante e l'arte 5, 2018 11-36, pp 17. 
personajes como San Brandán el Navegante, protagonista de uno de los viajes más conocidos de la cultura gaélica medieval. Si bien, con voluntad paródica, Pratt acaba desarticulando la realidad del personaje, la mecánica con la que el abad viajero explica su historia, ocultando al principio su rostro, podría ser la transcripción literal de un pasaje de la Comedia. ${ }^{9}$

¡“Geografías precisas”!, nos dice Iván Pintor. Sin duda veremos geografías muy precisas, reconocibles dentro de una historia que entremezcla mitos, leyendas, épocas históricas y tiempos ahistóricos, todo en un mundo onírico, que se refieren a la existencia de dos continentes perdidos: La Atlántida y Lemuria.

Y, en efecto en Mû,

Aúna coetáneamente la Atlántida y $\mathrm{Mu}(\mathrm{se}$ gún la versión del coronel Chuchward), que había encontrado la supuesta documentación en unas tablillas facilitadas por unos monjes del Tibet. Sin embargo y en otras versiones del tema (no entramos en la autenticidad de lo que cuentan) los dos continentes eran cosas bastantes distintas: Mu era un continente hundido en el Pacífico hace 40.000 años y la Atlántida (según la tradición platónica), en el Atlántico hace 11.500 años aproximadamente. ${ }^{10}$

La edición del libro a la que haremos referencia es la de Norma Editorial del 2008.

\section{La Atlántida y Mû}

Veamos, sin intención de ser exhaustivos, y solo como marco para entender mejor la novela gráfica que estamos analizando, las teorías que durante el siglo XIX se elaboraron sobre la Atlántida y Lemuria, de Mû y la forma en la que se entretejen en la obra de Hugo Pratt.
La Atlántida es una tierra desconocida entre Europa y América que representa la gloria perdida en la que se encuentran dos grandes mitos: la Edad de Oro y la Antigua Sabiduría.

Nos dice Umberto Eco:

Entre todas las tierras legendarias y a lo largo de los siglos, Atlántida es la que más ha estimulado la fantasía de filósofos, científicos o cazadores de misterios (cf. Albini, 2012).11

Hesíodo, en el siglo VIII a.C. ya nos habla de una raza que existía antes de la aparición de los dioses. Hinduistas, babilonios y la tradición judeo-cristiana tienen también esta Edad de Oro, esa antigua sabiduría en el Paraíso Terrenal. Pero, es sin duda Platón quien influencia con sus Diálogos a autores de todos los tiempos, como nos recuerda Umberto $\mathrm{Eco}^{12}$.

Dante se imaginó que se podría llegar al Paraíso navegando siempre hacia el oeste y 500 años más tarde William Blake retomó esta idea. A finales del siglo XIX, son Helena Petrovna Blavatski e Ignatius Donnelly los que vuelven a la Atlántida y la piensan como un continente perdido que es la base de los paralelismos que se dan entre Europa y América.

Otros especulan alrededor de una tierra perdida, bautizada como Lemuria por el geólogo Philip Sclater, que se situaría en medio del Pacífico y de la que solo se habría salvado la isla de Pascua. Volveremos más tarde sobre la isla de Pascua.

William Scott-Elliot aseguró que Lemuria fue destruida por la acción volcánica, pero que todavía existían los descendientes de los lemuritas. Los aborígenes australianos y los bosquimanos son algunos de ellos. Y finalmente, los atlantes evolucionaron a partir de los mejores lemuritas y sus principales descendientes fueron los toltecas, que medían casi dos metros de altura y tenían una capital de puertas doradas que actualmente se encuentra sumergida bajo el agua. Los toltecas se expandieron por América, Egipto y Britania y fueron los constructores de las pirámides y de Stonehenge.

9. op. cit. ibidem.

10. DÍEZ, HORACIO, Hugo Pratt. El esoterismo en Corto Maltés-2. Catálogo de esoterismos. http://comic-historietas.blogspot. com/2009/05/hugo-pratt-el-esoterismo-en-corto.html consultado el 10/06/2019

11. ECO, UMBERTO, Historia de las tierras y los lugares legendarios. pp 188.

12. op. cit. pp 190. 
Por otra parte, Brasseur de Bourbourg ${ }^{13}$ creyó haber descifrado la escritura maya y "tradujo" el relato de un cataclismo que había destruido un país llamado Mû. Todo ello interpretando erróneamente el Códice Troano. Y Pratt recupera la idea cuando Levi Columbia ${ }^{14}$ muestra "un antiguo manuscrito maya", que puede verse en la imagen 1, y Tristán Bantam ${ }^{15}$ responde:

- ¿Un continente destruido por el fuego y el mar, al occidente de Aztlán? Pero entonces... debe ser el mundo perdido de Mû. (Tristán Bantam $)^{16}$

Algunos identificaron Mû con Atlántida, pero James Churchward la identificaba con Lemuria y la situaba en el Pacífico. Como ya hemos comentado, solo la isla de Pascua ha sobrevivido.

Churchward nos dice en el prefacio del libro:

\begin{abstract}
All matters of science in this work are based on the translations of two sets of ancient tablets. Naacal tablets which I discovered in India many years ago, and a large collections of Stone tables, over 2500, recently discovered by William Niven in Mexico. ${ }^{17}$
\end{abstract}

Y el primer capítulo comienza así:

The garden of Eden was not in Asia but on a now sunken continent in the Pacific Ocean. The Biblical story of creation -the epic of the seven days and seven nights-came first not from the peoples of the Nile or of the Euphrates Valley but from this now submerged continent, $\mathrm{Mu}-$ the Motherland of Man. ${ }^{18}$

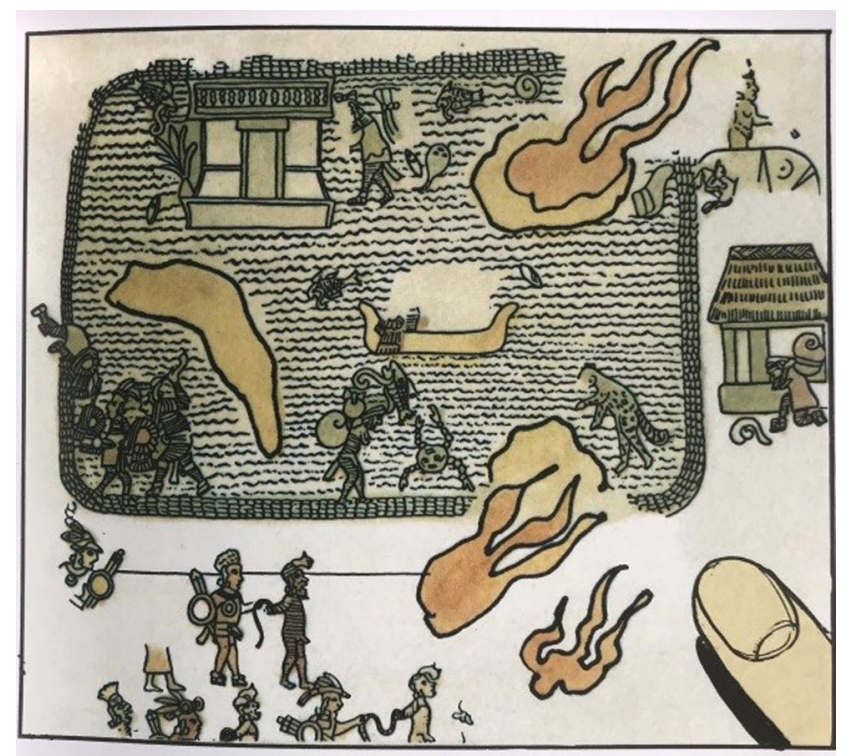

Imagen 1. Antiguo manuscrito que está en manos de Levi Columbia y que nos remite a la pintura mural del Templo de los Guerreros de Chichén Itzá, México. op. cit, pp. 107. Viñeta derecha.

Churchward nos habla de las colonias de Mû que surgieron en las distintas partes del mundo, asegurando haber encontrado rastros de dicha civilización en la zona maya. Rastros que halla el Corto Maltese. No es extraño, puesto que el mismo Hugo Pratt reconoce haber releído el libro de Churchward mientras preparaba el volumen.

Por su parte, Donnelly se basó para argumentar la existencia de la Atlántida en los textos de Platón, que nos habla de este continente en los dos conocidos diálogos: Timeo y Critias.

En Timeo, a través de Critias, habla de una Atenas mítica con una gran tradición de buen gobierno, que

13. El Códice Madrid, o Tro-Cortesiano, tuvo una historia diferente, ya que no fue sino hasta 1869-1870 que se publicó la sección conocida como Códice Troano, por el abad Charles Ettienne Brasseur de Bourbourg, quien además había localizado los fragmentos que actualmente conocemos como Relación de las cosas de Yucatán, escritos por fray Diego de Landa, donde se encuentra el ahora famoso alfabeto maya, así como su explicación sobre el calendario.

Fue con este alfabeto que Brasseur (1869-1870) trató de leer el Troano y, como hoy se sabe, identificó y leyó acertadamente un glifo muy importante (T1), el correspondiente al fonema u, "él", pronombre de tercera persona del singular, ya que la mayor parte de los textos glíficos mayas están escritos en tercera persona. En AYALA FALCÓN, MARICELA, De la procedencia y el uso del Códice Madrid (Tro-Cortesiano), Estudios de cultura maya, versión impresa ISSN 0185-2574, Estud. cult. maya vol.27, México 2006.

http://www.scielo.org.mx/scielo.php?pid=S0185-25742006000200001\&script=sci arttext, consultado 29/05/2019

14. Es un anticuario, dueño de un museo en Paramaribo, obsesionado con la búsqueda de El Dorado y la Tierra de Mú.

15. Tristán Bantam es el hijo de Ronald Bantam, un hombre obsesionado con la búsqueda de la tierra de Mú. A su muerte Tristán continúa la búsqueda.

16. op. cit. pp. 107, viñeta derecha.

17. Churchward, James. The Lost Continent of Mu.

18. op. cit. pp. 9 

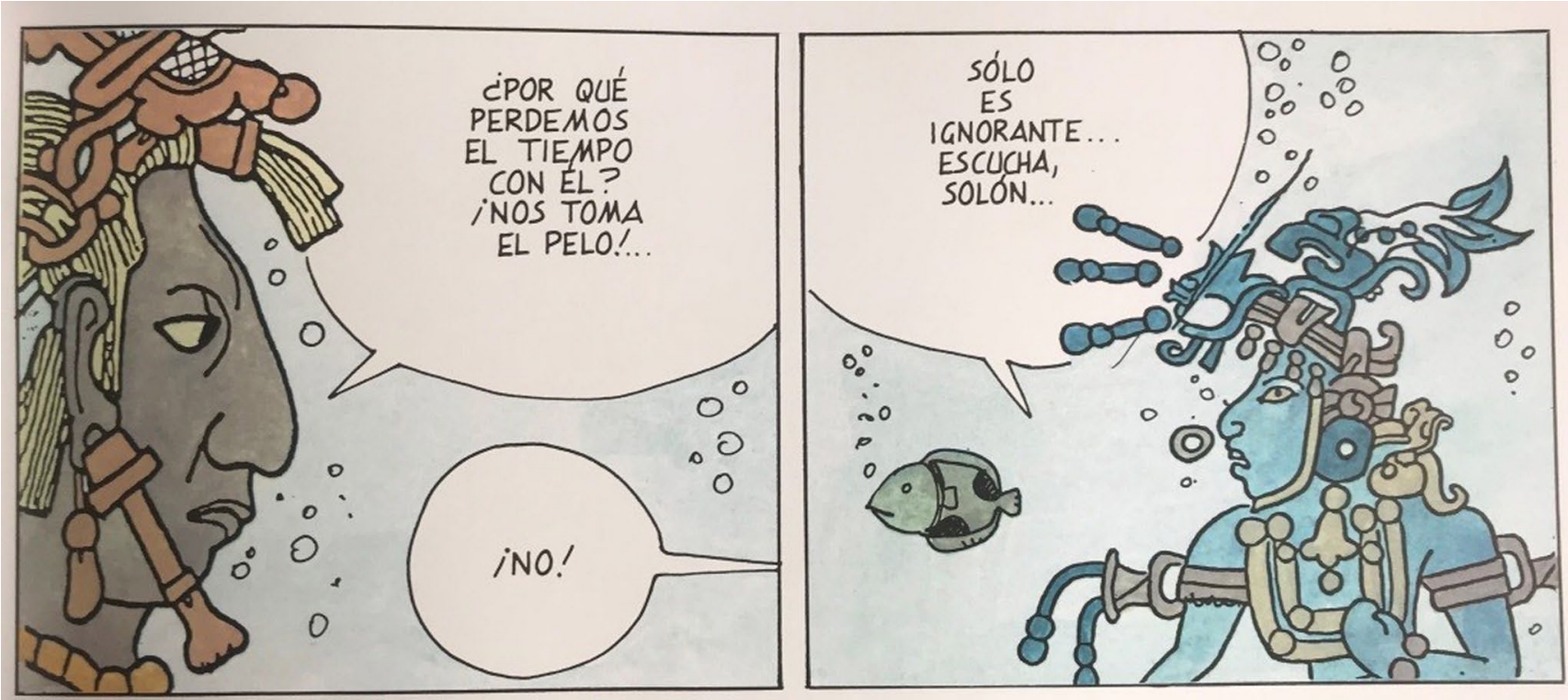

Imagen 2. Viñetas, al inicio de la historia, en las cuales Hugo Pratt rememora la Atlántida a traves de Timeo y Critias, haciendo clara referencia a los Diálogos de Platón. op cit. pp. 27

mantuvo una guerra con una gran potencia situada en una isla situada frente al estrecho de Gibraltar que tenía grandes dimensiones: la Atlántida. Finalmente, después de grandes terremotos y diluvios, la isla desapareció en el mar.

En Critias, Platón nos cuenta que la isla recibió este nombre de Atlas, una de las divinidades anteriores a Zeus. Poseidón toma posesión de la isla y se empareja con Clito con quien tiene 10 hijos. El primogénito es Atlas y a partir de ese momento los dirigentes de la isla se llamaran atlantes.

En Veinte mil leguas de viaje submarino (1879) de Jules Verne, en la cual el protagonista durante un paseo submarino se encuentra con unas ruinas que le parecen una antigua ciudad griega:

\section{¿Dónde estaba? ¿Dónde estaba? Quería saberlo a toda costa, quería hablar, quería arrancarme la esfera de cobre que aprisionaba mi cabeza. \\ Pero el capitán Nemo vino hacia mí y me contuvo con un gesto. Luego, recogiendo un}

trozo de piedra pizarrosa, se dirigió a una roca de basalto negro y en ella trazó esta única palabra: ATLANTIDA ${ }^{19}$

Y Hugo Pratt nos introduce en Mû a través de dos personajes a los que Corto ve pintados bajo el mar y que lo interpelan, tomándolo por Solón y explicándole el fin de la Atlántida:

\section{Habrás notado, oh Solón, que la continuidad de la civilización se ve interrumpida por las guerras y los cataclismos... ${ }^{20}$ \\ Una gran civilización resultó destruida mientras la Atlántida estaba en guerra... ${ }^{21}$}

En la siguiente viñeta, el personaje continúa su relato:

...con nosotros, los griegos primitivos. Toda la isla, más allá de las columnas de Hércules, se hundió en el gran océano... pero tú no escuchas....2

19. https://documentop.com/veinte-mil-leguas-de-viaje-submarino-biblioteca-virtual-universal 59f5b43d1723dd1386099dc0. $\underline{\text { html consultado } 1 / 5 / 2019}$

20. op. cit. pp 15, viñeta izquierda.

21. op. cit. pp 15, viñeta derecha.

22. op. cit. pp 16, viñeta izquierda. 
Corto, claramente sorprendido y mareado por culpa del nitrógeno de la escafandra, exclama, después de oír esto:

\section{No me parecéis muy griegos... ${ }^{23}$}

¡Claro! Son mayas, ¿cómo van a parecerle griegos? Mayas representados en pinturas murales sumergidas que, paradójicamente, a pesar de estar situadas bajo el agua, mantienen vivos sus colores. El marino les pregunta cuál es el motivo para mantenerse tan vivamente coloreados pese al agua salobre ${ }^{24}$.

Y el acercamiento de Corto al mito se asemeja muchísimo al modo en que Verne puso en contacto a sus protagonistas con el continente desaparecido en 20.000 leguas de viaje submarino, aunque tampoco es extraño que el rostro del Corto quedé enmarcado dentro de una escafandra de buzo porqué, como el mismo Pratt nos cuenta, es lo primero que recuerda haber dibujado:

...me hace recordar mi primer dibujo: tenía cinco años y mi padre me había enseñado a dibujar un submarinista. ${ }^{25}$

Volvamos a Donnelly, que se enfrentaba al problema de explicar la existencia de un continente desaparecido del cual no había vestigios y de situarlo de tal forma que demostrara su influencia sobre las culturas antiguas. Empleó el método que ya había prefigurado Helena Petrovna Bravatski, los paralelismos.

Las pirámides de Egipto y México tienen el mismo origen y la existencia de elefantes en América se pone de manifiesto en el Relieve de la estela B de Copán. Además, las mitologías egipcia y andina representan la religión original de la Atlántida, basada en el culto al sol.

En el cómic, Levi Columbia y Corto mantienen una conversación en referencia a paralelismos, al modo en que desaparecen civilizaciones por medio de cataclismos y de cómo han dejado huella en otras, historias demasiado bellas para no aceptarlas pero demasiado ingenuas para ser creídas $^{26}$, nos dice Corto.

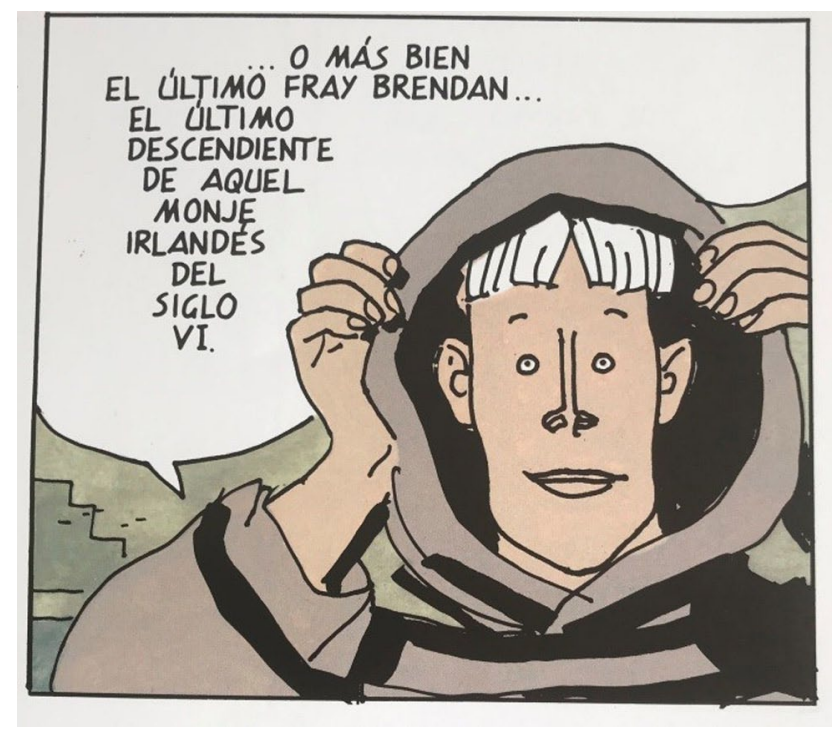

Imagen 3. San Brendan confiesa a Corto su secreto, no es el último sobreviviente de la Atlántida, es su descendiente. op.cit. pp 273. Viñeta derecha.

¿Y Quetzalcóatl? Podría tratarse de Brandán, Brendán o Brendano, un fraile irlandés que llegó a las costas de Florida en el siglo VI y que aparece en nuestra historia. Para Le Plongueon, Thomson y Brasseur de Bourbourg, es uno de los pocos supervivientes de la Atlántida.

Hugo Pratt, lo sitúa en su historia de manera magistral, como ya hemos avanzado más arriba. San Brandán niega ser Quetzalcoatl cuando le explica a Corto lo siguiente:

Sí, Quetzalcoatl, la serpiente emplumada, siempre ha regresado... cada año, y se marcha otra vez. ${ }^{27}$

Y acaba confesándole que no es de verdad San Brandán sinó un descendiente. ${ }^{28}$

Pero los orígenes de Quetzalcóatl los podríamos encontrar también en las migraciones de China. Existen $c a-$ racterísticas culturales semejantes con China, como serían

23. op. cit. pp. 16, viñeta derecha.

24. op. cit. pp. 25 , viñeta derecha

25. op. cit. Este texto pertenece al prólogo, que ha sido extraido del libro All'ombra di Corto. Hugo Pratt-conversazioni con Dominique Petitfaux- Rizoli, Milano Libri 1992.

26. op. cit. pp. 79 , viñeta derecha

27. op. cit. pp 270, viñeta derecha

28. op. cit., pp 18

29. OCAÑA JIMÉNEZ, LUCILA, El laberinto de Quetzalcóatl, Estudios Políticos, Núm. 3, Octava época, septiembre-diciembre, 2004, pp 66 
los banderines, objetos de jade de procedencia china, ciertas similitudes en los calendarios, [...]. ${ }^{29}$

Uno de los argumentos que refuerzan esta teoría tiene su origen en la cartografía china, en la cual encontramos América en cartas antiguas ${ }^{30}$. Y otro, quizás el más insinuante, es la similitud del dios con la serpiente emplumada china:

Sugiere Martínez Vargas que Quetzalcóatl es el dios de la pervivencia del tao tie, la serpiente emplumada de la mitología china, víbora volante, señor de los cielos y los mares, también frecuentemente representado por el dragon, $o$ com Xiuhcóatl, la serpiente de fuego. ${ }^{31}$

Pues bien, hacia el final de la novela gráfica, Hugo Pratt nos presenta a un personaje llegado del este, cerrando así el círculo. Emil Lassen, tiene por cliente a un anciano de nombre Soong, un chino rico que va en busca de Mû. El dialogo entre Corto y Lassen nos aclara muchas cosas:

- ¿...del pasado? Es un poco la misma historia de mi cliente, que busca el continente perdido de Mû. (Emil Lassen)

- ¿Mû? Ha dicho Mû... pero es increíble, también nosotros vamos en busca de Mû. (Corto Maltese $)^{32}$

- Mi cliente ha venido por el Pacífico y nosotros nos reunimos con él en Honduras. (Emil Lassen)

- Y nosotros vinimos por el Atlántico por la misma razón. (Corto Maltese) ${ }^{33}$

\section{Una breve aproximación al grafismo y a la iconografía de $M \hat{U}$ a través del lenguaje, de los personajes y del entorno}

Pero, ¿cómo aborda Pratt gráficamente la obra?, ¿De qué manera nos acerca a la historia?:

[...]: la aproximación óptica y narrativa, en una suerte de dolly movement, desde un grupo de figuras hasta un detalle muy concreto. En este caso, desde el exterior del marco de la

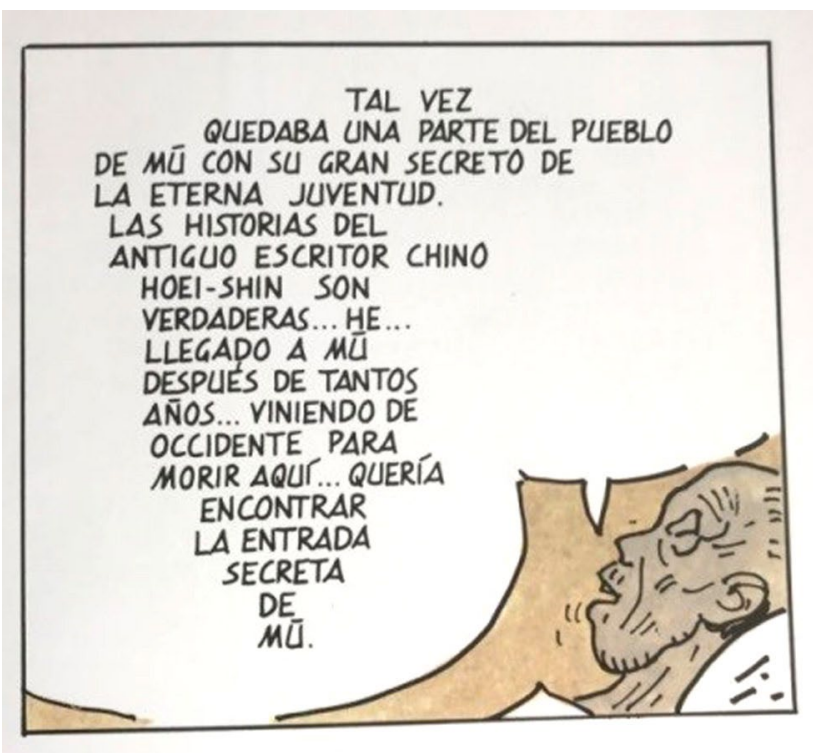

Imagen 4. El anciano moribundo hace referencia a un misionero budista, Hoei-Shin que, después de un largo viaje en el año 499 de nuestra era, habló de unas tierras al este de China que bien pudieran ser las costas de California. op. cit. pp. 491.

viñeta, un grupo de peces son instados a hablar acerca de una guerra mítica que opuso a atlantes y atenienses y de una catástrofe que acabó con la civilización atlante. A partir de la viñeta que reproduce con trazo deliberadamente tosco y línea pura el ojo de un pez, las siguientes ofrecen una serie de cortes sobre diferentes ojos y, después, un movimiento de apertura dividido en sucesivas viñetas sobre el rostro de la figura de un monarca en un códice maya.

El contraplano de esa secuencia es el rostro de Corto Maltés en el interior de una escafandra de buzo. Asiste, de hecho, a un trayecto que va de la imagen real en movimiento a la escritura, un camino que a lo largo de sus aventuras el marino suele recorrer en los dos sentidos. Merced a esa imagen se comprende que la voz que dialogaba con los peces correspondía a Corto. ${ }^{34}$ 


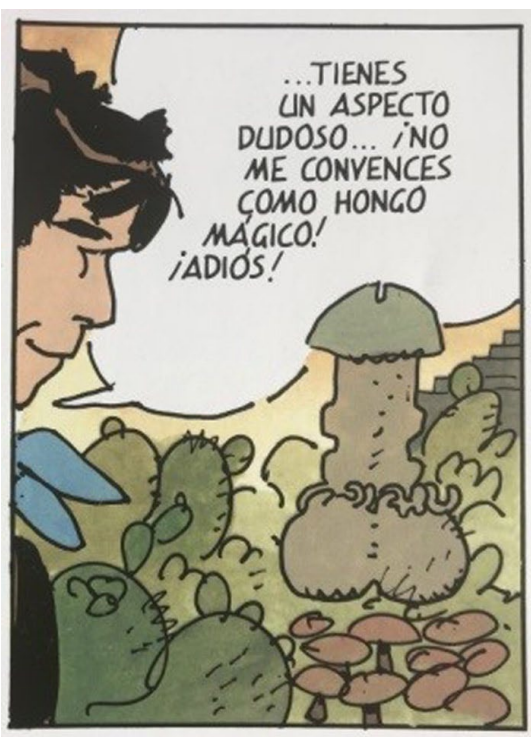

Imagen 5. Corto se encuentra frente a un campo de hongos, que nos recuerdan la escultura en forma de champiñón originaria del Valle de las Vacas en Guatemala (600100 aav. J.C) y que puede verse en el museo del quai Branly de París. op.cit. pp. 295.

Y juega también con los silencios. Uno de ellos, cuando la isla en la que se encuentra uno de los accesos a Mû, queda destruida, ayudándose de la repetición de las viñetas, otro donde el Corto se silencia luego de conversar con los moáis de la Isla de Pascua que sueñan y esperan mirando el cielo. ${ }^{35}$

En esta obra, el autor fusiona la arqueología mesoamericana, porque si bien, los principales personajes se inspiran en la iconografía maya, el entorno arquitectónico se compone también de elementos que provienen de diferentes civilizaciones.

El análisis de las imágenes permite reconocer personajes inspirados en los bajorrelieves, de Palenque y de Isla Mujeres.

Pero aunque sea rompiendo el hilo de la historia, queremos comenzar con un personaje que parece secundario, pero que guía al Corto Maltese por toda su aventura: la mariposa negra.

Y, a lo largo de la historia, va creciendo la importancia de los pictogramas. Uno de ellos representa a la mariposa nocturna

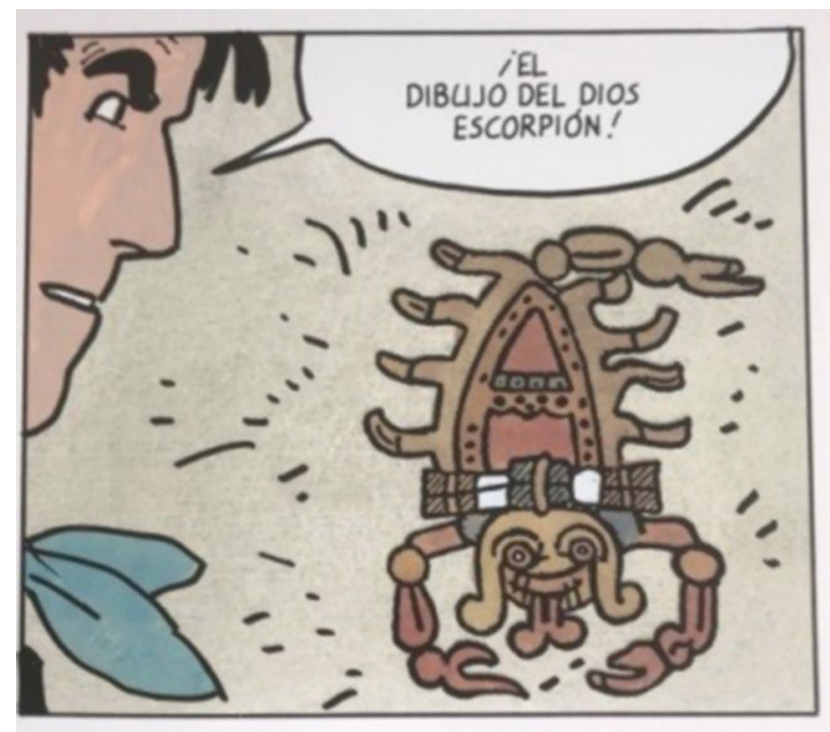

Imagen 6. Aquí vemos como para introduir al personaje, Pratt aprovecha un alacrán del códoce Laud. op. cit. pp.235, viñeta izquierda.

según el modelo de los códices mesoamericanos y se convierte en un personaje que guía a Corto a través del reino de los muertos. ${ }^{36}$

Otro, ${ }_{i}$ El dibujo del dios escorpión ${ }^{37}$ nos remite directamente al alacrán en un pronóstico de matrimonio del Códice Laud $^{38}$, y que introduce a los hombres escorpión en la historia.

En el caso de Teotihuacán, vemos a lo largo de varias viñetas unos fragmentos de pintura mural que proviene del templo de Tepantitla. Los olmecas, como padres de las civilizaciones mesoamericanas, tambén están presentes con una de las esculturas de cabezas colosales, identificable con el Monumento 1 de San Lorenzo Tenochtitlan. Los mixtecos colaboran con motivos inspirados en el códice Zouche-Nutall y con una máscara de mosaico de turquesa que Pratt convierte en un elemento decorativo arquitectónico.

Pratt lleva a cabo reproducciones fieles de sitios arqueológicos como Tikal y combina elementos provenientes del templo de las Máscaras de Kohumtlich. 


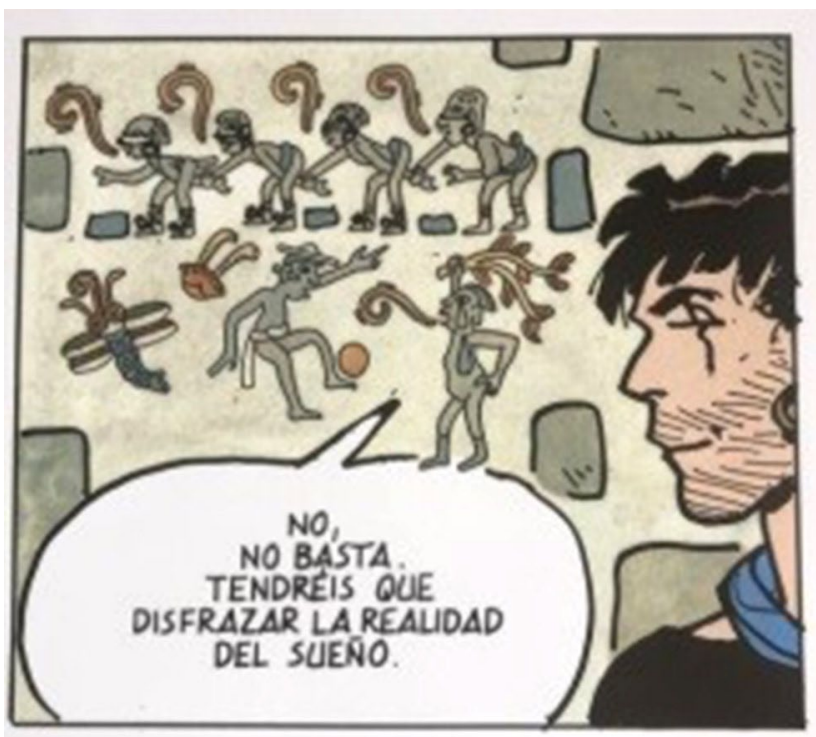

Imagen 7. En esta imagen puede verse una de las viñetas en la que aparecen claramente referenciadas las pintures murales de Tepantitla. op. cit. pp. 379, viñeta derecha.

\section{Conclusiones}

O album-síntese Mû reune, discute e reflete sobre as três facetas da dimensão da perda: o tesouro material (aventura transitiva do pirata) e o tesouro imaterial do conhecimento que determina a aventura intransitiva do explorador, prolongando-a e interiorizando-a em aventura

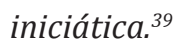

Es interesante la idea que nos ofrece Cristina Álvares como resumen a lo que Pratt desarrolla en Mû:

\section{[...], Quetzalcoatl, divindade azteca e maia, é Cuchulainn, herói divino ou semi-divino ir- landês que sugere uma origem comum para todas elas (Mû). Esta unidade do imaginá- rio humano diz-se em múltiplas narrativas a que Corto, ao longo das suas viagens, vai acedendo/tomando conhecimento/recons- tituindo. Deste modo, a impossibilidade de}
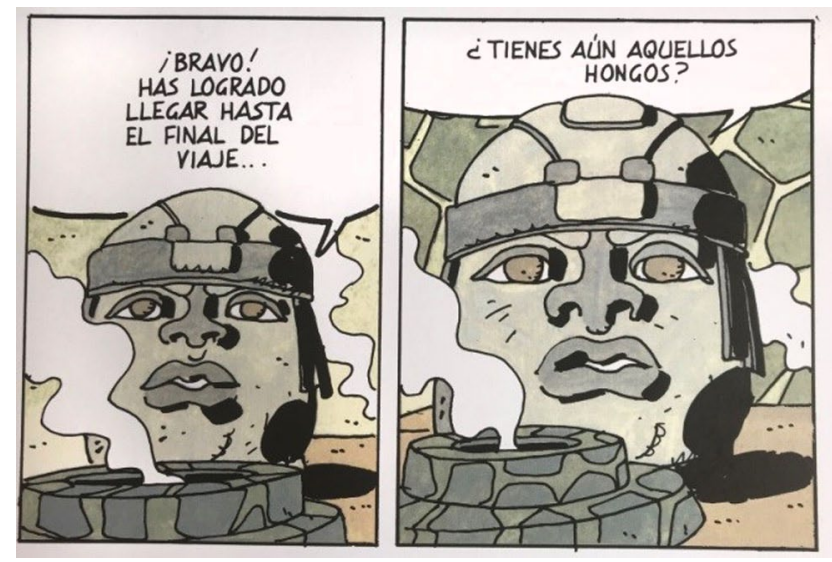

Imagen 8. Imagen en la cual el monumento 1 de San Lorenzo habla con el Corto Maltese sobre los hongos alucinogenos, que son los que le permiten, en parte, hacer su viaje por Mû. op.cit. pp. 347. Viñetas central y derecha.

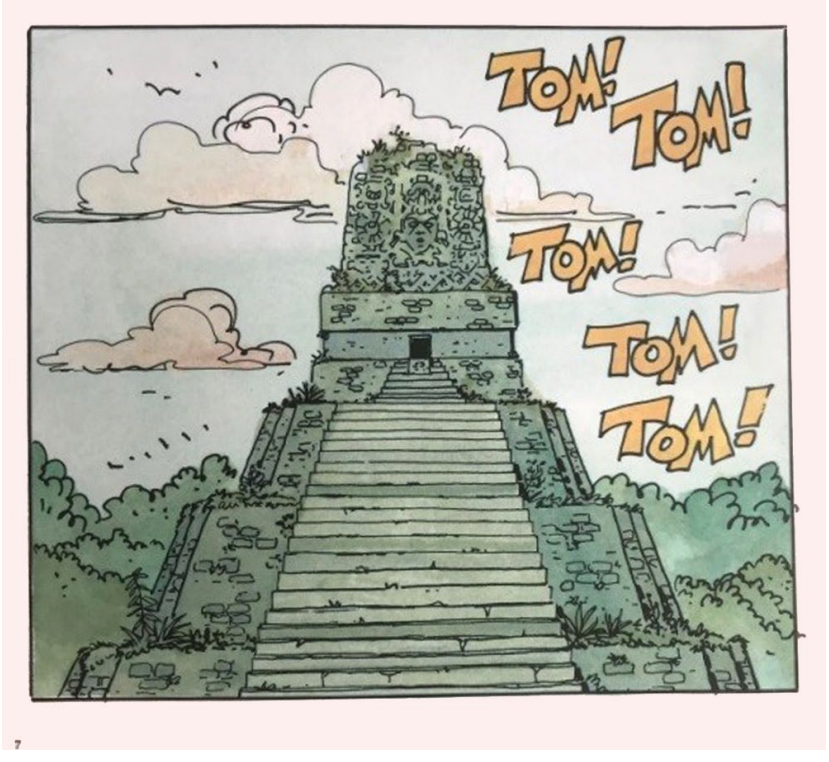

Imagen 9. Tikal y Kohumtlich combinados. op. cit. pp. 87.

recuperar o tesouro material torna possivel a revalorização e a reabilitação dos saberes précientíficos como saberes alternativos ao racionalismo occidental. ${ }^{40}$

39. ÁLVARES, CRISTINA. Corto Maltese. As morfologias da aventura. Literatura e Banda Desenhada - UC opcional do Mestrado em Mediação Cultural e Literária Introdução às aventuras de Corto Maltese, de Hugo Pratt. Aventuras, tesouros e saberes perdidos as fábulas entre objeto e símbolo. Corto, pirata e explorador

40. Op. Cit. 
Primer tercio del siglo XIX. Y es en ese momento en el que nos encontramos. Ninguna máquina del tiempo nos llevará al Clásico o al Postclásico. Nos acercamos a ellos a través de un mundo esotérico y mágico que está siempre presente en Mû.

Lo hacemos a través de un aventurero, el Corto Maltese, que ha recorrido los siete mares y que conoce todas las teorías respecto a los continentes perdidos de Mû y la Atlántida. Sin duda, el alter ego de Hugo Pratt es tan culto como él. Lo demuestra viñeta tras viñeta.

Ese conocimiento, tanto de las teorías como de los restos arqueológicos del mundo mesoamericano, convierten esta última aventura del Corto Maltese en un placer para todos aquellos enamorados de la Mesoamérica precolombina, con constantes guiños a olmecas, toltecas, teotihuacanos, y todo ello enmarcado en un paisaje indiscutiblemente maya.

Por otra parte, Hugo Pratt nos deja claro que Corto es perfectamente consciente que ese mundo perdido no existe más que en la imaginación de las personas, pero lo hace sin ningún ánimo de ridiculizar a aquellos teóricos de finales del XIX y principios del XX. Eso sí, con una ironía siempre presente que, en algunas ocasiones, desemboca en la parodia y nos devuelve a la realidad.

\section{Bibliografia}

Álvares, Cristina. Corto Maltese. As morfologias da aventura Literatura e Banda Desenhada - UC opcional do Mestrado em Mediação Cultural e Literária Introdução às aventuras de Corto Maltese, de Hugo Pratt Aventuras, tesouros e saberes perdidos - as fábulas entre objeto e símbolo, Corto, pirata e explorador

Ashe, Geoffrey, La Antlántida. Mitos, dioses, misterios. Ediciones del Prado, Madrid, 1993

Brancato, Sergio, Il diradarsi e il dissiparsi. Il rapporto di Pratt con il pubblico nella serialità-non seriale di Corto Maltese, H-ermes. Journal of Communication, H-ermes, J. Comm. 6 (2015), 9-18

ECO, UMBERTO, Historia de las tierras y los lugares legendarios

KarbovniK, DAmiEn, Le Réalisme Fantastique, une source d'inspiration sans commune mesure a $O$ imaginário esotérico. Literatura cinema banda desenhada. Edição do Centro de Estudos Humanísticos da Universidade do Minho @ EDIÇÕES HÚMUS, 2016

Códice Laud, 1994

Martínez Mendoza, Rolando, Silencios del corto maltés.

Menicocci, MARco, Uscire dalla Modernità. L'Odissea di Corto Maltese

OCAÑA JIMÉNEZ, LuCILA, El laberinto de Quetzalcóatl, Estudios Políticos, Núm. 3, Octava época, septiembre-diciembre, 2004

Pintor Iranzo, IvAN, El intervalo alucinatorio en las aventuras de Corto Maltés, de Hugo Pratt: la figuración de la palabra y la discontinuidad visual, H-ermes. Journal of Communication, H-ermes, J. Comm. 6 (2015), 31-58

Pintor Iranzo, Ivan, Somma Luce. Viajes al más allá y encuentros con la Diosa. Una aproximación comparada de la herencia dantesca en los cómics de Pratt, Fellini y Manara y Makyo, Dante e l'arte 5, 2018 11-36

Pratt, Hugo. Corto Maltese: Mû. Norma Editorial, $2008^{41}$ Purini, Sergio, L'Amérique plurielle de Hugo Pratt en Hugo Pratt. Lignes d'horizons, Catálogo de la exposición. Musée des Confluences, Lyon 2018, 102-139

Romano MARTín, YolANDA, 1975-2015 autores y personajes del cómic italiano en España, Transfer XI: 1-2 (mayo 2016), pp. 59-85.

Vidal-Naquet, Pierre, Atlantide. Breve storia di un mito. Eunaudi, Turín, 2005

\section{Fuentes en línea}

Maliyel Beverido Duhalt, Cabeza Colosal Número 1 (El Rey), Arqueología Mexicana, edición especial 22, Museo de Antropología de Xalapa, p. 24. https://arqueologiamexicana.mx/mexico-antiguo/ cabeza-colosal-numero-1-el-rey-san-lorenzo-veracruz

http://quadripop.blogspot.com/2017/01/saturno-contro-laterra.html , consultado 09/06/2019

http://www.briannissen.com/textosesp/mariposa.html consultado 21/05/2019

http://www.gaceta.udg.mx/G nota1.php?id=12750 consultado 21/05/2019

DíEz, Horacio, Hugo Pratt. El esoterismo en Corto Maltés-2. Catálogo de esoterismos. http://comic-historietas.blogspot.com/2009/05/hugo-pratt-el-esoterismo-en-corto. html consultado el 10/06/2019

41. Todas las imágenes que hemos incluido en este texto han sido extraídas de esta publicación. 